\title{
Analysis of Some Physiological and Biochemical Indices in Patients with Covid-19 Pneumonia Using Mathematical Methods
}

\author{
M. S. Gromov ${ }^{a}$, S. M. Rogacheva ${ }^{a, *}$, M. A. Barulina ${ }^{a, b}$, A. A. Reshetnikov ${ }^{c}$, \\ D. A. Prokhozhev ${ }^{a}$, and A. Yu. Fomina ${ }^{a}$ \\ a Saratov Medical University "Reaviz”, Saratov, Russia \\ ${ }^{b}$ Institute for Problems of Precision Mechanics and Control, Russian Academy of Sciences, \\ Saratov, Russia \\ ${ }^{c}$ V.I. Razumovsky Saratov City Clinical Hospital No. 2, Saratov, Russia \\ *e-mail:smro13@yandex.ru
}

Received August 3, 2021

Revised September 15, 2021

Accepted September 15, 2021

\begin{abstract}
The aim of the work was to conduct a retrospective analysis of the clinical data of patients with pneumonia caused by the SARS-CoV-2 virus, and to determine via mathematical methods the significance of some physiological and biochemical indices as predictive markers of an unfavorable outcome of the disease. A random cohort of patients with COVID-19 pneumonia numbered 209 people. Mathematical analysis addressed the physiological characteristics of patients recorded at the time of hospital admission, as well as blood coagulation parameters and those reflecting the development of an inflammatory reaction. The analyzed parameters were categorized relative to the reference ranges of physiologically normal values. Correlation analysis was carried out using categorical data on the disease outcome. The algorithms for calculating statistical characteristics, as well as results visualization, were programmed in Python. When comparing patient groups, the significance of differences between the determined parameters was assessed using the Pearson's $\chi^{2}$ test with Yates' correction. The study showed that the age over 50 and male sex can be considered risk factors for patients with COVID-19 pneumonia $(p<0.05)$. The disease outcome was found to be significantly affected by cardiovascular pathologies $(p<0.01)$ and to a lesser extent by diabetes mellitus $(p<0.10)$. There were revealed maximal correlation coefficients between the oxygen saturation level $(-0.43)$, as well as the breathing rate (0.43), and a fatal outcome of the disease. For patients over 50 years of age, oxygen saturation below $80 \%$ at the time of hospital admission turned out to be a marker of mortality. It was shown that D-dimer blood levels above $625 \mathrm{ng} / \mathrm{mL}$ in patients over 80 years of age correlated with mortal outcomes. No correlation was found between the C-reactive protein (CRP) level and the disease outcome. The effect of corticosteroids on the disease outcome was analyzed in patients with different CRP levels. It was found that, while using corticosteroids, the mortality rate in patients with CRP $\leq 12.5 \mathrm{mg} / \mathrm{L}$ is 2.7 times higher than in those with CRP $>12.5 \mathrm{mg} / \mathrm{L}(p<0.01)$. Thus, the use of adequate mathematical methods made it possible to define more precisely some mortality-associated physiological and biochemical indices in patients with COVID-19 pneumonia.
\end{abstract}




\section{DOI: $10.1134 / \mathrm{S} 0022093021060181$}

Keywords: COVID-19, pneumonia, physiological and biochemical indices, retrospective data, mathematical analysis

\section{INTRODUCTION}

SARS-CoV-2, a novel highly pathogenic $\beta$-coronavirus responsible for human coronavirus disease (COVID-19), was first detected in China in December 2019 and quickly spread around the world having caused a severe pandemic.

Active research is being carried out worldwide on the new virus and diseases it causes. The SARS-CoV-2 virion is known to consist of two main components, namely (1) a genomic RNA and a protein capsid, packed into a nucleocapsid, and (2) a phospholipid bilayer to surround the nucleocapsid. The phospholipid bilayer includes a spike protein (glycoprotein trimer), a hemaglutinin esterase enzyme, and few structural proteins (Spike, Envelope и Membrane) [1].

The virion interacts with a receptor, type II angiotensin-converting enzyme (ACE2); its binding to ACE2 is facilitated by the cellular type 2 transmembrane serine protease (TMPRSS2), which activates the S-protein of the virus. ACE2 and TMPRSS2 are presented on the surface of various cells of the respiratory organs, esophagus, intestines, heart, adrenals, urinary bladder, hypothalamus and pituitary gland, endothelium, and macrophages [2, 3]. This leads to a variety of clinical manifestations of the disease [4].

The infection is mainly transmitted via respiratory droplets (airborne transmission), less often via direct person-to-person contact (contact transmission). The incubation period is $1-14$ days with a peak around 3-7 days; during the latency period, the virus becomes highly contagious. Patients exhibit flu-like symptoms, sore throat, fever, cough, fatigue, and dyspnea; in some cases, patients develop gastrointestinal problems, such as diarrhea and vomiting [5, 6]. When alveolar epithelial cells are affected, patients develop pneumonia (15\% of cases), acute respiratory distress syndrome (ARDS) and, in most severe cases, multiple organ dysfunction syndrome $(5 \%$ of cases) $[1,4]$.

ARDS is caused by an aggressive inflammatory reaction of the human immune system, which develops in response to the release of viral particles after their reproduction in infected cells. This reaction consists in cytokine overproduction, which leads to the development of an immune over-reaction called a cytokine storm [7]. Elevated cytokine levels promote the influx of immune cells, such as macrophages, neutrophils, and $\mathrm{T}$ cells, from the bloodstream to the site of infection; this process has a destructive effect on human tissues, causing lung damage and severe ARDS, which manifests itself in low oxygen saturation levels and is an important cause of death in COVID-19 patients [6, 7]. An increased level of $\mathrm{C}$-reactive protein (CRP) in the blood of patients serves an indicator of the presence of an acute phase of the inflammatory response [4].

COVID-19 patients are known to have disorders of the blood coagulation and fibrinolytic systems. In patients with moderate and severe COVID-19, i.e. with poor outcome, there were noted an increase in the D-dimer level, a decrease in the prothrombin time (PT) and activated partial thromboplastin time (APTT) [8, 9]. Since these changes in hemostasis correspond to disseminated intravascular blood coagulation, COVID-19 is believed to be associated with venous or arterial thrombosis [10].

Elderly people and people with comorbidities, such as diabetes, hypertension, pulmonary diseases, asthma, bronchitis and cardiovascular diseases, are prone to developing ARDS and thrombosis, and it is they who become the main "hostages" of SARS-CoV-2 [6].

The COVID-19 pandemic continues, and a large number of patients are admitted to hospitals with serious lung damage. That is why it is so important to reveal and specify the physiological signs of the disease, which must receive special attention when treating patients in order to prevent its severe development and fatal outcome. Mathematical methods of analysis are highly instrumental in determining to what extent certain physiological and biochemical indices are 
significant in predicting the disease, in choosing a treatment and care strategy.

Recently, there has been an outbreak of publications, whose authors propose predictive models of mortality and severe disease progression risk in patients with COVID-19. The review [11] analyzes 107 such models, of which the authors distinguished only one model, the 4C (Coronavirus Clinical Characterization Consortium) Mortality Score, as promising [12]. For all other models, a high risk of bias assessment was determined, mainly due to unrepresentative selection of control patients, post-randomization patient exclusions, and vague medical reporting [11]. The authors believe that currently it is impossible to recommend any model for practical use, and further research should focus on verifying, comparing, improving and updating the best versions, as well as specifying the predictors of disease severity.

The aim of the work was to carry out a retrospective analysis of the clinical data of patients with pneumonia caused by SARS-CoV-2 and, using mathematical methods, to determine the significance of some physiological and biochemical indices as predictive markers of an unfavorable outcome of the disease.

\section{MATERIALS AND METHODS}

We used encrypted epicrises of patients with a confirmed diagnosis of COVID-19 and pneumonia, provided by the V.I. Razumovsky Saratov Clinical Hospital No 2. The patients were hospitalized from September 1 to December 1, 2020 and received treatment in accordance with the temporary recommendations of the Ministry of Health of the Russian Federation, which included etiotropic, anticoagulant, immunosuppressive and symptomatic therapy. A random cohort of patients (209 people) was used for analysis.

Patients were divided into five age categories, namely $1-18<35$ years of age; $2-35<50$ years of age; $3-50<65$ years age; $4-65<80$ years age; and $5-\geq 80$ years age. The analysis also took into account the sex of each patient and the presence of comorbidities, such as diabetes, cardiovascular (CV) pathology, and oncological disease. By the sign "sex", female and male patients were assigned to categories 1 and 0 , respectively. By the signs "CV disease", "diabetes" and "oncology", the patients with any of these diseases were assigned to category 1 , without these diseases-to category 0 .

For a comparative mathematical analysis, we used the physiological and biochemical indices recorded in the epicrises, the values of which were compared with normal reference values (Table 1).

The analyzed indices were divided into categories relative to their reference ranges. The results corresponding to normal reference values were taken as 0 ; upward deviations from the maximum normal value by $10,20,30 \%$, etc. were recorded as 10, 20, 30 etc., downward deviations from the minimum normal value were recorded as -10 , $-20,-30$, etc.

Correlation diagrams were plotted according to categorical data on the disease outcomes: in the range from 0 to 1 , the probability of fatal outcome increases with an increase in the index category; in the range from 0 to -1 , the probability of fatal outcome increases with a decrease in the index category. Algorithms for calculating statistical characteristics were programmed in Python using the numpy and pandas libraries for mathematical and statistical analysis (https://numpy.org/, https://pandas.pydata.org/pandas-docs/stable/).

The obtained results were visualized also in Python using the seaborn and mathplotlib libraries (http://seaborn.pydata.org/, https://matplotlib.org/). The target variable in data analysis was the outcome of the disease: discharged or deceased.

The significance of differences in the parameters when comparing patient groups was assessed using the Pearson's $\chi^{2}$ test with Yates' correction, which is introduced to reduce the number of distortions when dealing with small samples [13]. In some cases, the significance of the results was assessed using one-way ANOVA and Fisher's $F$-test. At the probability level $p>0.10$, the difference was considered statistically nonsignificant [14].

The studies were carried out in compliance with international and Russian ethical principles and standards, and were approved by the Ethics Committee at the Medical University "Reaviz." 
Table 1. Some physiological and biochemical indices determined during the treatment of COVID-19 patients and their normal reference values

\begin{tabular}{|c|c|c|c|}
\hline No. & Indices & Designation & Reference values \\
\hline 1 & Oxygen saturation, $\%$ & Sat & $>94$ \\
\hline 2 & Heart rate, $\min ^{-1}$ & Heart_rate & $60-80$ \\
\hline 3 & Breathing rate, $\min ^{-1}$ & Breath_rate & $16-20$ \\
\hline 4 & Systolic blood pressure, $\mathrm{mm} \mathrm{Hg}$ & Sistolic_BP & $120-130$ \\
\hline 5 & Diastolic blood pressure $\mathrm{mmHg}$ & Diastolic_BP & $75-80$ \\
\hline 6 & Body temperature, ${ }^{\circ} \mathrm{C}$ & Temp & 36.6 \\
\hline 7 & Body mass index, $\mathrm{kg} / \mathrm{m}^{2}$ & BM_index & $18-25$ \\
\hline \multicolumn{4}{|c|}{ Inflammation markers } \\
\hline 8 & C-reactive protein, mg/L & CRP & $0-5$ \\
\hline \multicolumn{4}{|c|}{ Blood coagulation markers } \\
\hline 9 & Activated partial thromboplastin time, $\mathrm{s}$ & APTT & $22.5-35.5$ \\
\hline 10 & Prothrombin index, $\%$ & PI & $73-122$ \\
\hline 11 & Fibrinogen, $\mathrm{g} / \mathrm{L}$ & Fibrinogen & $2-4$ \\
\hline 12 & Prothrombin time, $\mathrm{s}$ & PT & $11-15$ \\
\hline 13 & D-dimer, ng/mL & D-dimer & $<250$ \\
\hline
\end{tabular}

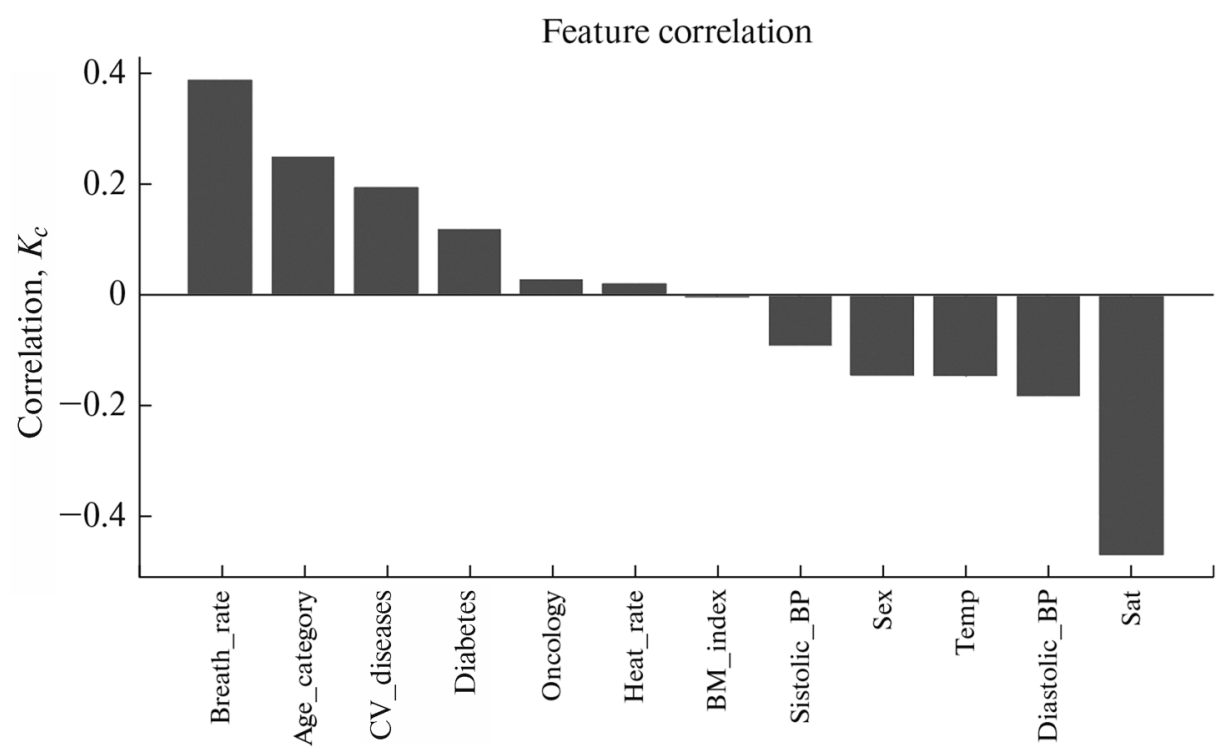

Fig. 1. A diagram of correlation between the physiological parameters of patients and the disease outcome.

\section{RESULTS}

Initially, a diagram of the correlation between the physiological parameters of patients (209 people) and an unfavorable prognosis of their disease was plotted (Fig. 1). The diagram shows that the poor disease outcome depends to the largest extent on the oxygen saturation level (Sat) (correlation coefficient $K_{c}=-0.43$ ) and breathing rate (Breath_rate; $K_{c}=0.39$ ). These parameters are interrelated, namely an increased breathing rate in COVID-19 patients, as a rule, correlates with a decreased oxygen saturation level.

To a lesser extent, an unfavorable outcome cor- 


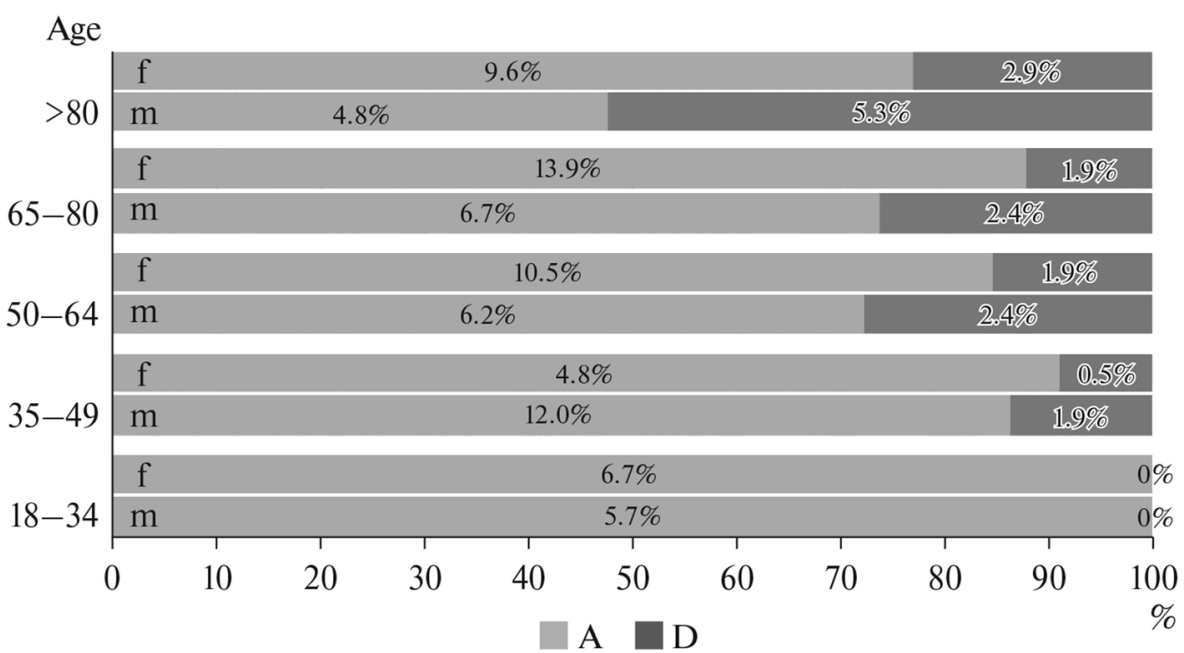

Fig. 2. Distribution of the patients by sex ( $m-$ male, $\mathrm{f}-$ female), age, and disease outcome (A-alive, D-deceased). The horizontal axis shows the mortality rate in each age category of patients. The diagram shows the percentage of favorable and fatal outcomes across the entire cohort (209 patients).

Table 2. Impact of comorbidities on the disease outcome

\begin{tabular}{c|c|c|c|c}
\hline \multirow{2}{*}{\multicolumn{2}{c|}{ Comorbidity }} & \multicolumn{2}{c|}{ Number of patients } & $\begin{array}{c}\text { Significance of the impact of comor- } \\
\text { bidity on outcome }\end{array}$ \\
\cline { 3 - 5 } \multicolumn{2}{c}{} & discharged & deceased & $\chi^{2}$ \\
\hline \multirow{3}{*}{ CV } & + & 104 & 34 & 6.93 \\
Diabetes & - & 65 & 6 & 3.02 \\
& + & 30 & 12 & 0.027 \\
\hline \multirow{3}{*}{ Oncology } & - & 139 & 28 & \\
& + & 17 & 5 & 35 \\
\hline
\end{tabular}

relates with the patient's age $\left(K_{c}=0.25\right)$, namely the higher the age category, the higher the probability of fatal outcome, the presence of a cardiovascular $(\mathrm{CV})$ disease $\left(K_{c}=0.20\right)$ or diabetes $\left(K_{c}=0.16\right)$, and a decreased arterial diastolic blood pressure (Diastolic_BP) $\left(K_{c}=-0.19\right)$. In the center of the diagram, there are the indices that correlate least with the disease outcome, e.g., heart rate (Heart_rate) and body mass index (BM_index). Therefore, the correlation matrix allows us to compare the impact of indices on the disease outcome and distinguish the most significant of them.

Figure 2 shows the distribution of patients (209 people) by sex and age, with the disease outcome indicated. Among the patients, there were more females (110) than males (99). The diagram shows that more than $47 \%$ of patients were over 65 years of age. The mortality rate was calculated across the entire cohort. In age group 1, no fatal outcomes were recorded. The mortality rate increased with age, being the highest among males in each group. Overall, $19.2 \%$ of patients ( 40 people) deceased, of which $12.0 \%$ were males and $7.2 \%$ females. The highest mortality rate was recorded among males over 80 years of age (52.4\% of the total number of patients in this category).

Most inpatients had comorbidities (Table 2): CV diseases-66\%, diabetes-20\%, and cancer$11 \%$. Table 2 shows that CV pathology $(p<0.01)$ has a significant impact on the disease outcome, while diabetes has it to a lesser extent $(p<0.1)$.

The impact of obesity on the outcome of 
Table 3. Impact of oxygen saturation (Sat), as determined in patients of different ages at the time of hospital admission, on the disease outcome

\begin{tabular}{|c|c|c|c|c|c|c|c|}
\hline \multirow[b]{2}{*}{ Age category } & \multicolumn{3}{|c|}{ Favorable disease outcome } & \multicolumn{3}{|c|}{ Fatal disease outcome } & \multirow[b]{2}{*}{$p$} \\
\hline & $\begin{array}{c}\text { number of } \\
\text { patients }\end{array}$ & $\underset{\%}{\operatorname{mean} \text { sat }} \pm \mathrm{S}$ & median Sat & $\begin{array}{c}\text { number of } \\
\text { patients }\end{array}$ & $\begin{array}{c}\text { mean sat } \\
\% \mathrm{~S}\end{array}$ & median sat & \\
\hline $18<35$ years of age & 26 & $95.2 \pm 4.2$ & 97.0 & 0 & - & - & - \\
\hline $35<50$ years of age & 35 & $95.0 \pm 3.7$ & 96.0 & 5 & $95.2 \pm 4.0$ & 97.0 & 0.812 \\
\hline $50<65$ years of age & 35 & $94.3 \pm 3.7$ & 95.0 & 9 & $86.2 \pm 9.3$ & 87.0 & 0.001 \\
\hline $65<80$ years of age & 43 & $93.0 \pm 4.9$ & 95.0 & 9 & $89.8 \pm 7.1$ & 92.0 & 0.026 \\
\hline$\geq 80$ years of age & 30 & $91.3 \pm 6.0$ & 93.0 & 17 & $79.9 \pm 10.5$ & 80.0 & 0.0003 \\
\hline
\end{tabular}

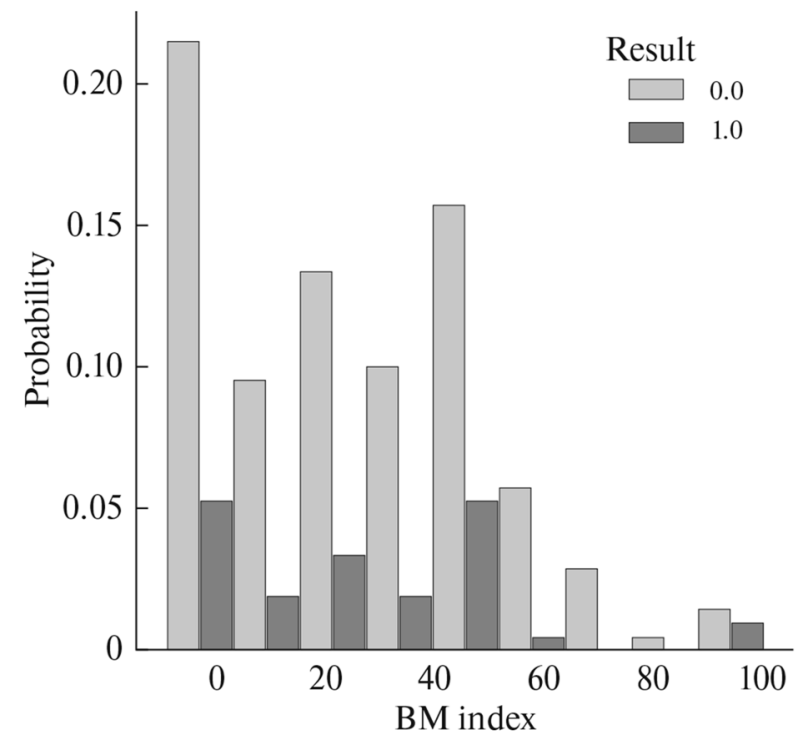

Fig. 3. Probability of favorable (0) and fatal (1) disease outcomes, depending on the deviation of their body mass index (BM_index) from the normal reference values, $\%$.

COVID-19 was considered. In the given patient cohort (209 people), 73\% had an increased body mass index (BMI). We obtained a distribution of recovered and deceased patients, depending on the deviation of this index from normal reference values (Fig. 3), which reveals no significant impact of the degree of obesity on the disease outcome.

We divided all the patients into two groups, namely with a BMI within the range of normal reference values (56 people in total, 11 deceased) and an increased BMI (153 people in total, 29 deceased), and evaluated statistically the impact of overweight on the fatal disease outcome. No significant impact of BMI deviations

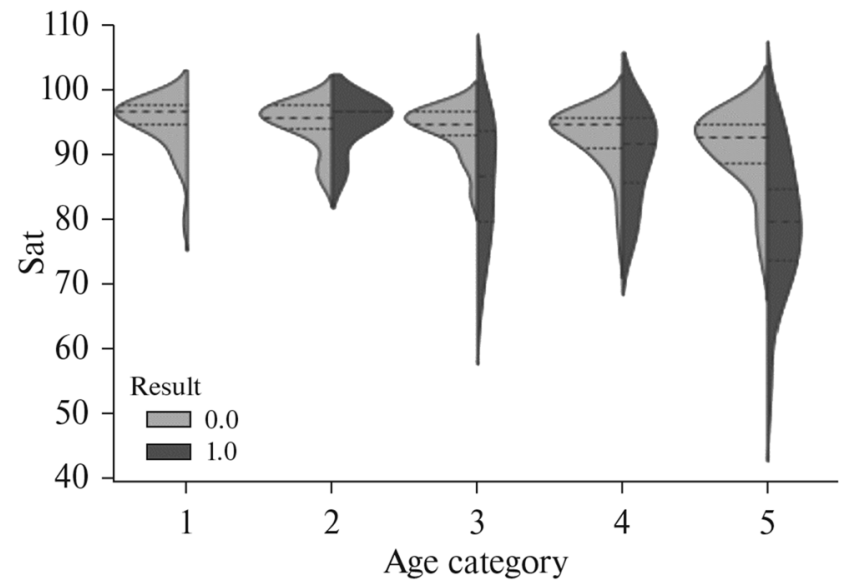

Fig. 4. Violin diagram reflecting the dependence of the disease outcome $(0$-discharged, 1 -deceased) on the oxygen saturation level (Sat) and the age category of patients: 1.0$18<35$ years of age; $2.0-35<50$ years of age; $3.0-50<$ 65 years of age; $4.0-65<80$ years of age; $5.0-\geq 80$ years of age.

from the normal reference values on mortality was found $\left(\chi^{2}(1, n=209)=0.0126, p=0.911\right)$.

The impact of oxygen saturation on the disease outcome was examined. The results of mathematical analysis are presented in the form of a violin diagram (Fig. 4). This statistical diagram is used to visualize data distribution and their probability density. Each violin represents a group of variables in the same data category. A bell-shaped distribution signifies normal distribution.

Figure 4 and Table 3 show that in most of the recovered patients the oxygen saturation level at the time of hospital admission was above $85 \%$, with the mean and median values being within the ranges of 91.3-95.2 and 93-97\%, respectively. It 


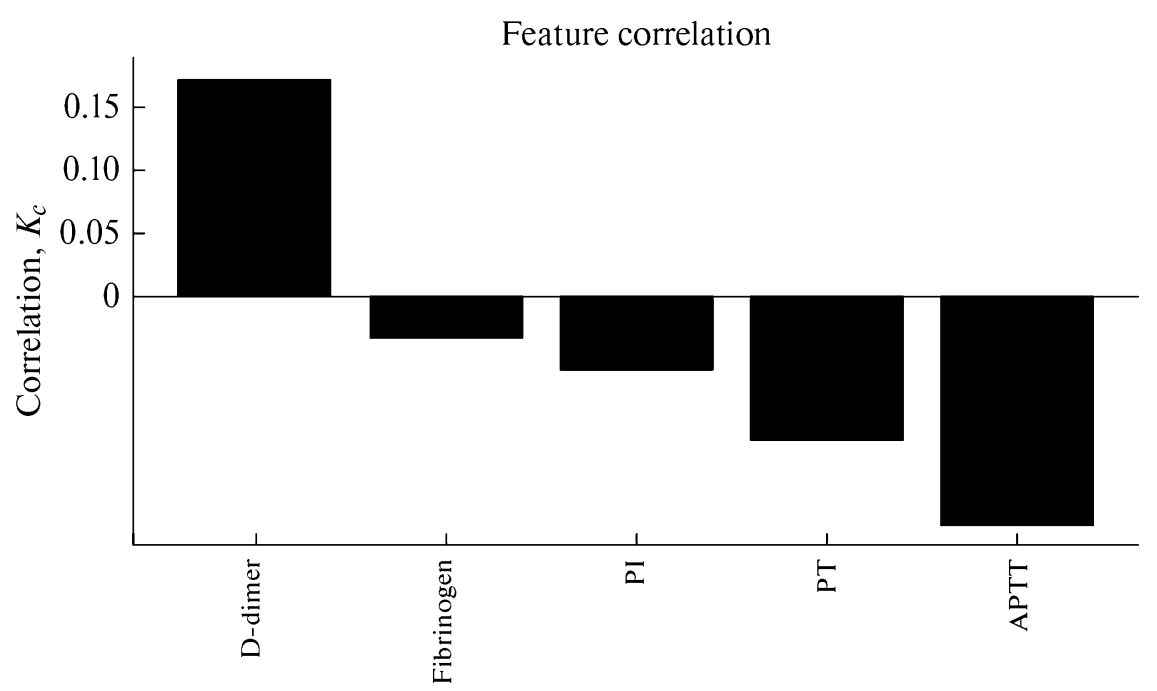

Fig. 5. A diagram of correlation between blood coagulation indices and the disease outcome.
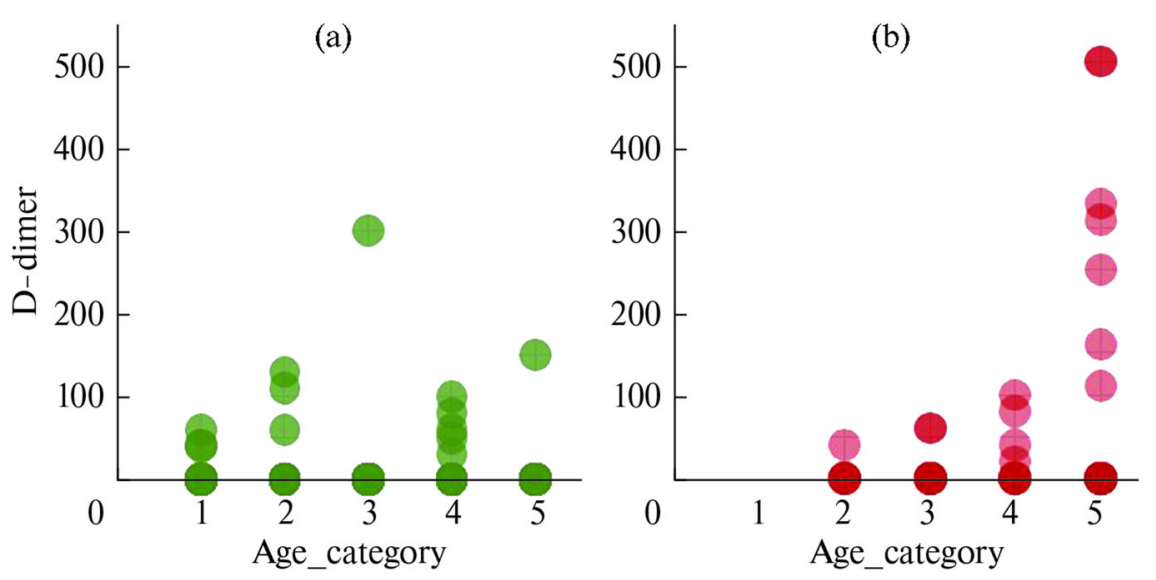

Fig. 6. Dependence of the disease outcome on an excess of the D-dimer blood level relative to its normal reference values and on the age of patients: $1-18<35$ years of age; $2-35<50$ years of age; $3-50<65$ years of age; $4-65<80$ years of age; $5-$ $\geq 80$ years of age. (a) Discharged, (b) deceased.

can also be seen that the mean value of the oxygen saturation level in the discharged patients decreases with age.

The distribution curve of the oxygen saturation index in the deceased patients from age group 2 does not differ from that in the recovered patients (Fig. 4), while the mean Sat values in these groups coincide (Table 3). Apparently, the condition of these patients sharply deteriorated after hospitalization.

The violin diagram shows a significant scatter of the saturation indices in deceased patients from the three older groups. Their mean Sat level is within $86.2-79.9 \%$, decreasing with age. It was noted that for patients over 50 years of age, an oxygen saturation below $80 \%$ became a marker of mortality $(p<0.01)$.

We explored the correlation of blood coagulation indices with the disease outcome (Fig. 5) using the data of 79 patients. As follows from the diagram, the unfavorable outcome of the disease correlates to a large extent with an increase in the concentration of D-dimer $\left(K_{c}=0.17\right)$ and a decrease in APTT $\left(K_{c}=-0.17\right)$.

The impact of the D-dimer blood concentration in patients of different age groups on the disease outcome was considered in more detail. The whole group consisted of 79 patients ( 39 fatal outcomes). In Fig. 6, the dependence of the disease outcome on the D-dimer level and the age of the patients is presented as a scatter plot. The diagram shows that a significant increase in the D-dimer 


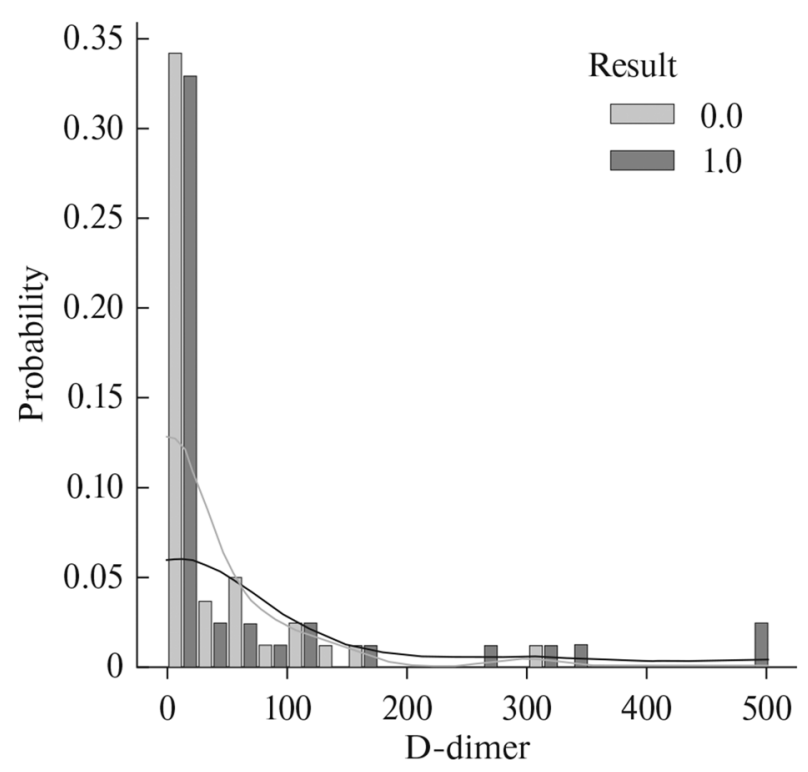

Fig. 7. Probability of favorable (0) and fatal (1) disease outcomes, depending on the excess of the D-dimer blood level relative to the range of normal reference values.

level was mainly found in patients over 80 years of age, and these patients deceased in most cases; therefore, for the patients of this age group, a $150 \%$ increase in the concentration of D-dimer became a marker of mortality. In patients of other age categories, an increase in the D-dimer level by more than 2 times was rarely observed, and there were no fatal outcomes among them.

Figure 7 shows that at a normal D-dimer level, the number of favorable and unfavorable outcomes is almost the same, but at a D-dimer level exceeding the normal reference values by $300 \%$, the mortality rate is $100 \%$ (all these patients belong to age group 5) (Fig. 6).

A statistical analysis of the data obtained revealed no significant differences in the probability of fatal outcomes at a normal D-dimer level and that at its increased level $\left(\chi^{2}(1, n=79)=\right.$ 0.023 with Yates' correction, $p=0.879)$. Apparently, this is due to a small sample size, which comprised nearly all fatal outcomes (39).

We carried out a statistical analysis of APTT indices of 186 patients. In most of the deceased patients (34 people), this index was within a reference range, while in 5 patients it exceeded the normal level, and there was no significant difference in the probability of fatal outcomes between these categories of patients $\left(\chi^{2}(1, n=186)=\right.$

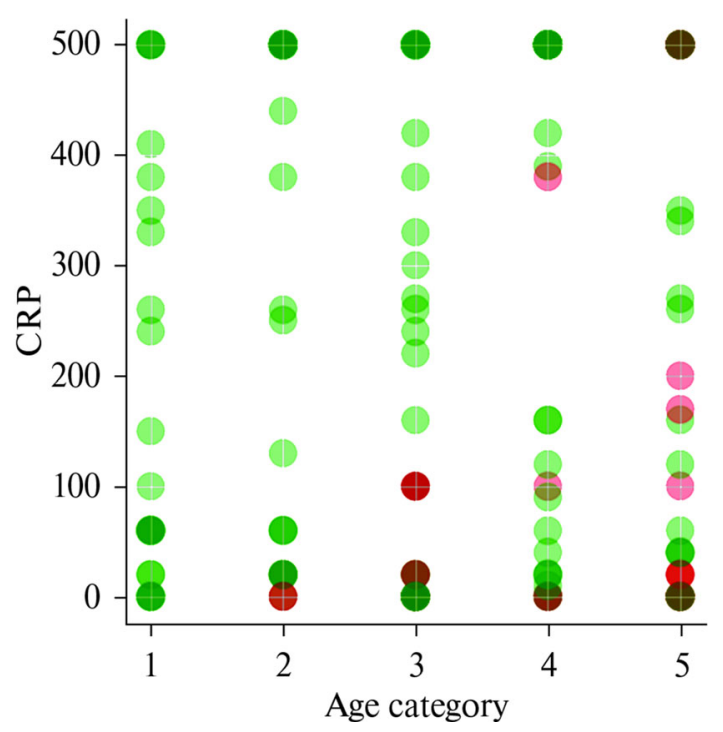

Fig. 8. Dependence of the outcome of the disease (reddeceased, green-discharged) on the excess of the C-reactive protein (CRP) concentration in the blood relative to the norm and on the age of patients: $1-18<35$ years old; $2-35$ $<50$ years old; $3-50<65$ years old; $4-65<80$ years old; $5-\geq 80$ years old.

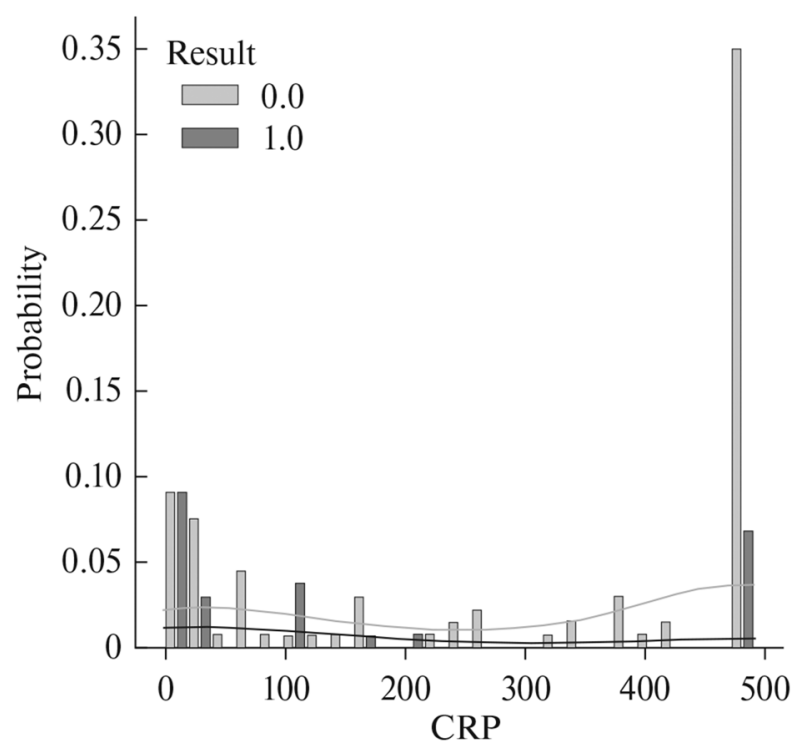

Fig. 9. Probability of favorable (0) and fatal (1) outcome of the disease, depending on the excess of the C-reactive protein (CRP) blood level relative to normal reference values during corticosteroid treatment.

0.841 with Yates' correction, $p=0.359)$. All patients (14 people), who had the APTT index below the normal level, recovered, apparently due to anticoagulant therapy. Therefore, the APTT value cannot serve a marker of mortality. 
Table 4. Disease outcome in patients with different blood levels of C-reactive protein, depending on the corticosteroid administration; an assessment of the significance of differences between CRP index values in patient groups

\begin{tabular}{|c|c|c|c|c|}
\hline \multirow{4}{*}{ Disease outcome } & \multicolumn{4}{|c|}{ Number of corticosteroid-treated patients } \\
\hline & \multicolumn{2}{|c|}{ used } & \multicolumn{2}{|c|}{ not used } \\
\hline & $\mathrm{CRP} \leq 12.5 \mathrm{mg} / \mathrm{L}$ & $\mathrm{CRP}>12.5 \mathrm{mg} / \mathrm{L}$ & $\mathrm{CRP} \leq 12.5 \mathrm{mg} / \mathrm{L}$ & $\mathrm{CRP}>12.5 \mathrm{mg} / \mathrm{L}$ \\
\hline & $a$ & $b$ & $c$ & $d$ \\
\hline favorable & 33 & 66 & 21 & 22 \\
\hline fatal & 21 & 11 & 4 & 3 \\
\hline Columns & \multicolumn{4}{|c|}{ Significance of differences in signs when comparing patient groups } \\
\hline$a$ and $b$ & \multicolumn{4}{|c|}{$\chi^{2}(1, n=181)=9.118$ with Yates' correction, $p=0.0025$} \\
\hline$a$ and $c$ & \multicolumn{4}{|c|}{$\chi^{2}(1, n=181)=3.148$ with Yates' correction, $p=0.076$} \\
\hline$b$ and $d$ & \multicolumn{4}{|c|}{$\chi^{2}(1, n=181)=0.002$ with Yates' correction, $p=0.963$} \\
\hline$c$ and $d$ & \multicolumn{4}{|c|}{ a small number of observations } \\
\hline
\end{tabular}

The next indicator to be considered was C-reactive protein (CRP). We analyzed the dependence of the disease outcome on its blood level in 181 patients of various ages. It is shown in Fig. 8 as a parameter scatter plot. The diagram shows that patients recovered and deceased with very different CRP values, i.e. no correlation was found in this case, however, we noted a significant mortality in patients with low CRP levels.

Therefore, we decided to find out how the administration of corticosteroids (intramuscular injections of prednisolone or dexamethasone) affects the disease outcome in patients with different CRP levels. Figure 9 shows the normalized distribution of patients (181 people) with favorable and lethal outcomes of the disease, depending on their CRP blood level during corticosteroid therapy. As follows from the diagram, the number of deceased patients accounts for more than $50 \%$ of the total number of patients with low CRP levels $(0-5 \mathrm{mg} / \mathrm{L})$. Most of the fatal outcomes corresponded to the CRP concentration range of $0-$ $12.5 \mathrm{mg} / \mathrm{L}$.

We carried out a comparative analysis of the distributions of patients whose therapy either included or excluded the administration of antiinflammatory steroids. The CRP concentration of $12.5 \mathrm{mg} / \mathrm{L}$ was used as a limiting value (Table 4).

From Table 4 it can be seen that among the corticosteroid-treated patients with CRP blood con- centrations $\leq 12.5 \mathrm{mg} / \mathrm{L}, 38.9 \%$ deceased; while of the patients who did not receive steroids, only $16 \%$ deceased; the significance of differences was determined at $p<0.10$. If the CRP blood level was above $12.5 \mathrm{mg} / \mathrm{L}$, then the mortality rate during hormone therapy was $14.3 \%$, while $12 \%$ of patients deceased in the absence of corticosteroid therapy; in this case, the significance of differences cannot be determined due to a small number of observations. The significance of differences in the mortality rate of patients treated with corticosteroids and having a blood CRP level $\leq 12.5 \mathrm{mg} / \mathrm{L}(38.9 \%)$ and $>12.5 \mathrm{mg} / \mathrm{L}(14.3 \%)$ was determined at $p<0.01$.

Thus, with the administration of corticosteroids, the mortality rate in patients with CRP level $\leq 12.5 \mathrm{mg} / \mathrm{L}$ was 2.7 times higher than in those with CRP $>12.5 \mathrm{mg} / \mathrm{L}(p<0.01)$.

\section{DISCUSSION}

Recently, there has been an increase in the number of COVID-19 patients with pneumonia signs. COVID-19 pneumonia is specifically characterized by a damage to interstitial (connective) tissue and (in an acute form of the disease) pulmonary alveoli, a frequent bilateral lung injury, the appearance of affected lung areas visualized by computer tomography as ground-glass opacities, a high degree of respiratory failure, rapid progres- 
sion. In addition to lung injury, some other organs often becomes affected, such as the liver, kidneys, heart, and hematopoietic system, which indicates the presence of systemic inflammation [5, 6]. These features correlate with the pathogenesis of COVID-19, namely, the development of an extremely strong inflammatory response of the organism to viral particles, which affects the organism's own immune cells, causing ARDS and multiple organ failure [7].

With an ever increasing flow of COVID-19 patients, any markers signaling an unfavorable development of the disease are taking on special significance [11]. Such markers can be revealed and their parameters can be specified when doing a research on representative samples of patients using adequate methods of statistical and correlation analyses.

Within the framework of a retrospective study of the epicrises of patients with pneumonia caused by SARS-CoV-2 (a random cohort of 209 people), we analyzed the physiological parameters of patients to be obligatorily studied at the moment of hospital admission, as well as the markers of blood coagulation and inflammatory response, i.e. those physiological processes that are most affected by COVID- 19 .

A correlation diagram (Fig. 1) plotted on the basis of such patients' parameters as the age, sex, presence of comorbidities ( $\mathrm{CV}$ and oncological diseases, diabetes), and seven additional physiological characteristics (Table 1) made it possible to reveal those physiological indices that correlate most with an unfavorable outcome of the disease, such as age $\left(K_{c}=0.25\right)$, the presence of concomitant diseases $\left(K_{c}=0.16-0.20\right)$, and oxygen saturation $\left(K_{c}=-0.43\right)$. These parameters were analyzed in more detail.

Specifically, it was shown that the mortality rate among the patients hospitalized with pneumonia rises with their age (Fig. 2). For example, in group $18<35$ years of age ( 26 people), no fatal outcomes were recorded; in the group $35<$ 50 years of age (40 people), they accounted for $12.5 \%$; in group $50<65$ years of age ( 44 people)$20.5 \%$, in group $65<80$ years of age ( 52 people) $-17.3 \%$, and in group $>80$ years of age (47 people) $-36.2 \%$. It was also noted that among the patients of the three older groups ( $>50$ years of age), there were almost 1.5 times more females than males, whilst the mortality rate was 2.2 times lower: $16.5 \%$ of unfavorable outcomes were recorded in the female group and $36.2 \%$ in the male group $(p<0.05)$. In male group 3 , there were $27.8 \%$ fatal outcomes, in male group $4-26.3 \%$, and in male group older than 80 years of age (21 people) $-52.4 \%$.

Our results are consistent with the data of other authors who distinguished an old age and male sex as unfavorable outcome risk factors in COVID-19 $[11,12,15]$. For example, a meta-analysis including 3027 SARS-CoV-2-infected patients [16] demonstrated that for male smokers aged over 65 years, this disease is most dangerous. In the present study, it was shown with a sufficient degree of significance $(p<0.05)$ that the age over 50 years and male sex can be considered as risk factors for patients with diagnosed SARS-CoV-2caused pneumonia.

When considering the effect of comorbidity on disease outcomes, we divided the concomitant diseases into three categories: cardiovascular pathology, diabetes, and oncology, without diagnosis detailization. Of the patients studied, 97\% had at least a single above-listed pathology, many had a history of several diseases; for example, $90 \%$ of patients with diabetes had a CV pathology. During statistical analysis, we considered the impact of each disease category separately (Table 2). It was shown that CV pathology had a significant impact on the disease outcome $(p<$ $0.01)$. Mortality in the group of such patients was 3 times higher than in patients without CV diseases. Mortality in diabetic patients was 1.7 times higher than in non-diabetic patients $(p<0.10)$. The impact of an oncological disease on the disease outcome was not significant $(p>0.10)$, although the absence of a statistically significant correlation in this case may be due to the small number of observations.

Many authors note CV disease as the most significant factor worsening the prognosis in COVID-19 patients. It was found that deceased patients exhibited a highest occurrence of arterial hypertension and CV diseases [17]; arterial hypertension was found to be the most unfavorable pathology in terms of prognosis [18]; ischemic heart disease is also in the list of diseases with a 
highest mortality rate $(26.3 \%)$ [15].

The effect of diabetes mellitus type 2 on the disease outcome is discussed in detail in several studies $[15,19]$, where an almost twofold increase in mortality was reported for COVID-19 patients. Our data are consistent with these results.

We failed to reveal a significant impact of overweight on the disease outcome, as evidenced by the results of our analysis shown on the correlation diagram (Fig. 1) and as a normalized distribution (Fig. 3), as well as by a statistical assessment of the significance of differences in the parameters studied. In Ref. [15], there was also found no significant difference in the body mass index between discharged and deceased patients: the mean BMI in discharged and deceased patients was 32.9 and $30.9 \mathrm{~kg} / \mathrm{m}^{2}$, respectively. However, it is noteworthy that the majority of patients $(73 \%)$ with moderate and severe COVID-19 forms are overweight. Obesity as a significant risk factor for an unfavorable outcome of COVID-19 was noted in the work by Mexican authors [18].

A decrease in oxygen saturation down to $95 \%$ (with normal values of 98-99\%) is known to be an indication for hospitalization of COVID-19 patients in Russia [20]. A drop in this index evidences a decrease in one of the main functions of the lungs, namely oxygen transfer from the air to the blood. A decrease in oxygen saturation in COVID-19 patients is usually accompanied by dyspnea, which manifests itself in an increased breathing rate. We revealed maximum correlation coefficients for the saturation level $\left(K_{c}=-0.43\right)$ and breathing rate $\left(K_{c}=0.43\right)$, interrelated physiological parameters, with a fatal outcome (Fig. 1). A detailed analysis of the correlation between the saturation level of discharged and deceased patients and their age (Fig. 4, Table 3) revealed the following regularities. The saturation level at the time of hospital admission was above $85 \%$ in the majority of recovered patients; with age, the average oxygen saturation level in discharged patients decreased from 95.2 to $91.3 \%$; in deceased patients, the average saturation level, depending on the age category, was $86.2-79.9 \%$, and in patients older than 50 years of age, the saturation level below $80 \%$ at the time of hospital admission became a marker of mortality $(p<$
$0.01)$. It should be noted that dyspnea as the main symptom of COVID-19 pneumonia is mentioned in many publications $[5,6,16,17]$. The breathing rate and oxygen saturation are among the eight major predictors when building a prognostic model of the fatal outcome of the disease [12].

In addition to severe hypoxia, coagulopathy with the development of disseminated intravascular coagulation (DIC) syndrome was reported in COVID-19 patients [21]. Therefore, when hospitalizing patients with suspected or confirmed COVID-19, experts recommend to determine blood levels of D-dimer, fibrinogen and other parameters of the blood coagulation system, to count the number of platelets in the blood, and, only in accordance with the test results, to prescribe antithrombotic therapy [21]. It is well known that the $\mathrm{D}$-dimer blood level exceeding the upper limit of normal values more than 2 times indicates an increased risk of deep vein thrombosis of the lower extremities and thromboembolism of the pulmonary arteries [10, 21]. In COVID-19 patients, it was proposed to consider the D-dimer blood level high if it is 3-4 times higher than the upper limit of the reference range, and extremely high if this limit is exceeded by 5-6 times or more [21]. The D-dimer level of $1 \mathrm{mg} / \mathrm{mL}$ was included into a predictive model of mortality in COVID-19 [22].

In the present study, we analyzed the parameters of the blood coagulation system as predictors of mortality (Fig. 5). In a sample of 79 patients, highest correlation coefficients were established for D-dimer $\left(K_{c}=0.17\right)$ and APTT $\left(K_{c}=-0.17\right)$, i.e. with an increase in the D-dimer blood level and a decrease in activated partial thromboplastin time (APTT), the probability of the fatal outcome increases. It was found that an increase in the D-dimer concentration by more than 2.5 times relative to normal reference values $(>625 \mathrm{ng} / \mathrm{mL})$ in patients over 80 years of age correlates with a fatal outcome (Fig. 6). In patients of other age categories, such an excess was rarely recorded, and there were no fatal outcomes among them. No statistically significant difference was found between the probability of a lethal outcome at the normal D-dimer level and that at an increased D-dimer level, perhaps due to the insufficient number of observations (79 patients, of which, 
39 were lethal outcomes). Similar results were obtained in the statistical analysis of the APTT index (186 patients). Apparently, antithrombotic therapy is quite efficacious.

The main cause of death in COVID-19 is an aggressive systemic inflammatory response (cytokine storm). This is indicated by the correlation of the COVID-19 severity and mortality with the level of cytokines, including interleukin (IL)-6 and IL-8; a similar phenomenon was found in previous studies of the Middle East respiratory syndrome (MERS) and severe acute respiratory syndrome (SARS) [23]. In patients infected with pathogenic human coronaviruses, a cytokine storm promotes acute lung injury and the development of ARDS [1, 4, 23]. Therefore, controlling cytokine storm has been proposed as a vital treatment strategy for COVID-19 patients, especially in severe cases $[23,24]$.

Anti-inflammatory cytokines boost the synthesis of CRP, a glycoprotein produced in the liver and referred to acute-phase proteins. Its blood concentration increases 10-100 times within 24$48 \mathrm{~h}$ after the onset of inflammation [25]. As a rule, the CRP blood level is monitored in admitted patients; therefore, it is this protein that we considered as an indicator of the development of the inflammatory process. It should be noted that the CRP level is considered in many predictive models of the fatal outcome risk in COVID-19 $[11,12,22]$.

The data of 181 patients were used for statistical analysis. There was found no correlation between the CRP level and the disease outcome, although there was a significant number of fatal outcomes at a normal level of this protein (Fig. 8). Therefore, the impact of corticosteroids (prednisolone or dexamethasone injected intramuscularly) on the disease outcome was analyzed in patients with different CRP levels. As is known, corticosteroids can be used to suppress a cytokine storm, however, based on data obtained from MERS and SARS patients, their administration did not improve survival, but rather slowed down viral clearance [23, 24].

Our statistical analysis showed (Table 4) that the use of corticosteroids at a CRP level $\leq 12.5 \mathrm{mg} / \mathrm{L}$ is more likely to lead to a fatal outcome than their absence in therapy at this CRP level $(p<0.10)$ and than their use at a CRP level $>12.5 \mathrm{mg} / \mathrm{L}(p<0.01)$. The impact of corticosteroids on the outcome of the disease with a CRP level $>12.5 \mathrm{mg} / \mathrm{L}$ was not statistically confirmed, probably due to the small number of observations. Therefore, at a CRP blood level below $12.5 \mathrm{mg} / \mathrm{L}$, the use of corticosteroids may lead to a worsening of the COVID-19 patients' condition, which is consistent with the results reported elsewhere [23, 24].

Thus, the use of adequate computer programs and mathematical methods allowed us to analyze a significant array of physiological and biochemical indices in COVID-19 pneumonia patients and to reveal some patterns that can be used in clinical practice and further studies of this new infectious disease.

\section{STUDY LIMITATIONS}

The limitations are concerned with a retrospective design of this study. Not all laboratory studies were carried out in all patients, so subsamples varied in the number of patients. Moreover, laboratory test values may be distorted by a prior outpatient treatment of these patients. Interpretation of our results may also be limited due to the relatively small size of the general sample.

\section{CONCLUSION}

The conducted mathematical analysis of the retrospective data from 209 patients with pneumonia caused by SARS-COV-2 enabled specification of some physiological and biochemical parameters predicting an unfavorable outcome of COVID-19, such as the age over 50, male sex, the presence of cardiovascular diseases, oxygen saturation below $80 \%$ for patients over 50 years, D-dimer blood level 2.5 times exceeding the upper limiting value of the reference range for patients over 80 years of age. It was also noted that a CRP blood level below $12.5 \mathrm{mg} / \mathrm{L}$, the use of corticosteroids may lead to an increased likelihood of fatal outcome.

\section{AUTHORS' CONTRIBUTION}

The idea of the research and discussion of the 
results (M.S.G.); experimental design, discussion of the results, and writing the manuscript (S.M.R.); data collection (D.A.P., A.Yu.F.); mathematical data processing, graphical data presentation, and discussion of the results (M.A.B.); discussion of the results (A.A.R.).

\section{FUNDING}

This work was carried out within the framework of the research program "A search for indicators of COVID-19 clinical course severity" planned at the Saratov Medical University "Reaviz".

\section{CONFLICT OF INTERESTS}

The authors declare that they have no conflicts of interest related to the publication of this article.

\section{REFERENCES}

1. Mishra SK, Tripathi T (2021) One year update on the COVID-19 pandemic: Where are we now? ActaTropica 214:10577. https://doi.org/10.1016/ j.actatropica.2020.105778

2. Ou X, Liu Y, Lei X, Li P, Mi D, Ren L, Guo L, Guo R, Chen T, Hu J, Xiang Z, Mu Z, Chen X, Chen J, Hu K, Jin Q, Wang J, Qian Z (2020) Characterisation of spike glycoprotein of SARSCoV-2 on virus entry and its immunecrossreactivity with SARS-CoV-2. Version 2. Nature Communicat 11(1):1620. https://doi.org/10.1038/ s41467-020-15562-9

3. Hoffmann M, Kleine-Weber H, Schroeder S, Kru N, Erichsen S, Schiergens TS, Herrler G, Wu N, Nitsche A, Mu MA, Drosten C, Pohlmann S (2020) SARS-CoV-2 cell entry depends on ACE2 and TMPRSS2 and is blocked by a clinically proven protease inhibitor. Cell 181(2):271-280. https://doi.org/10.1016/ j.cell.2020.02.052

4. Frolova EV, Filippova LV, Uchevatkina AV, Ponomarenko VA, Borzova YuV, Shurpitskaya OA, Taraskina AE, Gaykovaya LB, Fedorenko AS, Gomonova VV, Latariia EL, Vasilyeva NV (2021) Immunological features of patients with COVID-19, depending on the severity of the disease. Problems of medical mycology 23(1):3-13. (In Russ).

5. Chen N, Zhou M, Dong X, Qu J, Gong F, Han Y, Qiu Y, Wang J, Liu Y, Wei Y, Xia J, Yu T,
Zhang X, Zhan L (2020) Epidemiological and clinical characteristics of 99 cases of 2019 novel coronavirus pneumonia in Wuhan, China: a descriptive study. Lancet 395: 507-513. https:// doi.org/10.1016/S0140-6736(20)30211-7

6. Huang C, Wang Y, Li X, Ren L, Zhao J, Hu Y, Zhang L, Fan G, Xu J, Gu X, Cheng Z, Yu T, Xia J, Wei Y, Wu W, Xie X, Yin W, Li H, Liu M, Xiao Y, Gao H, Guo L, Xie J, Wang G, Jiang R, Gao Z, Jin Q, Wang J, Cao B (2020) Clinicalfeaturesofpatientsinfectedwith 2019 novelcoronavirusinWuhan, China. Lancet 395: 497-506. https:// doi.org/10.1016/S0140-6736(20)30183-5

7. Ragab D, Eldin SH, Taeimah M, Khattab R, Salem R (2020) The COVID-19 Cytokine Storm; What We Know So Far. Front Immunol 11:1446. https://doi.org/10.3389/fimmu.2020.01446

8. Guo T, Fan Y, Chen M, Wu X, Zhang L, He T, Wang H, Wan J, Wang X, Lu Z (2020) Cardiovascular implications of fatal outcomes of patients with coronavirus disease 2019 (COVID-19). J.A.M.A. Cardiology 5(7): 811-818. https:// doi.org/10.1001/jamacardio.2020.1017

9. Zhou F, Yu T, Du R, Fan G, Liu Y, Liu Z, Xiang J, Wang Y, Song B, Gu X, Guan L, Wei Y, Li H, Wu X, Xu J, Tu S, Zhang Y, Chen H, Cao B (2020) Clinical course and risk factors for mortality of adult inpatients with COVID-19 in Wuhan, China: a retrospective cohort study. Lancet 395(10229):1054-1062. https://doi.org/10.1016/ S0140-6736(20)30566-31

10. Kanorskii SG (2021) COVID-19 and the heart: direct and indirect impact. Kuban Scient Med Bull 28(1):16-31. (In Russ). https://doi.org/ 10.25207/1608-6228-2021-28-1-16-31

11. Wynants L, Van Calster B, Collins GS, Riley RD, Heinze G, Schuit E, Bonten MMJ, Dahly DL, Damen JA, Debray TPA, de Jong VMT, De Vos M, Dhiman P, Haller MC, Harhay MO, Henckaerts L, Heus P, Kammer M, Kreuzberger N, Lohmann A, Luijken K, Ma J, Martin GP, McLernon DJ, Navarro CLA, Reitsma JB, Sergeant JC, Shi C, Skoetz N, Smits LJM, Snell KIE, Sperrin M, Spijker R, Steyerberg EW, Takada T, Tzoulaki I, van Kuijk SMJ, van Bussel BCT, van der Horst ICC, van Royen FS, Verbakel JY, Wallisch C, Wilkinson J, Wolff R, Hooft L, Moons KGM, van Smeden M (2020) Prediction models for diagnosis and prognosis of covid-19: systematic review and critical appraisal. BMJ 369:m1328. https:// doi.org/10.1136/bmj.m1328

12. Knight SR, Ho A, Pius R, Buchan I, Carson G, Drake TM, Dunning J, Fairfield CJ, Gamble C, 
Green CA, Gupta R, Halpin S, Hardwick HE, Holden KA, Horby PW, Jackson C, Mclean KA, Merson L, Nguyen-Van-Tam JS, Norman L, Noursadeghi M, Olliaro PL, Pritchard MG, Russell CD, Shaw CA, Sheikh A, Solomon T, Sudlow C, Swann OV, Turtle LCW, Openshaw PJM, Baillie JK, Semple MG, Docherty AB, Harrison EM (2020) Risk stratification of patients admitted to hospital with covid-19 using the ISARIC WHO Clinical Characterisation Protocol: development and validation of the 4C Mortality Score. BMJ 370:m3339 https://doi.org/ 10.1136/bmj.m3339

13. Cramér H (1975) Mathematical methods of statistics. Mir, M. (In Russ).

14. Greenwood PE, Nikulin MS (1996) A guide to chi-squared testing. JohnWiley\&Sons, NewYork.

15. Demidova TY, Lobanova KG, Perekhodov SN, Antsiferov MB, Oynotkinova OS (2021) Clinical and laboratory characteristics of patients with COVID-19 and concomitant type 2 diabetes. Cardiovascular Therapy and Prevention 20(1):2750. (In Russ). https://doi.org/10.15829/1728-88002021-2750

16. Zheng Z, Peng F, Xu B, Zhao J, Liu H, Peng J, Li Q, Jiang C, Zhou Y, Liu S, Ye C, Zhang P, Xing Y, Guo H, Tang W (2020) Risk factors of critical \& mortal COVID-19 cases: A systematic literature review and meta-analysis. Journal of Infection 81(2): e16-e25. https://doi.org/ 10.1016/j.jinf.2020.04.021

17. Chen $\mathrm{T}, \mathrm{Wu} \mathrm{D}$, Chen $\mathrm{H}$, Yan $\mathrm{W}$, Yang $\mathrm{D}$, Chen G, Ma K, Xu D, Yu H, Wang H, Wang T, Guo W, Chen J, Ding C, Zhang X, Huang J, Han M, Li S, Luo X, Zhao J, Ning Q (2020) Clinical characteristics of 113 deceased patients with coronavirus disease 2019: retrospective study. Br Med J 368:m1091. https://doi.org/10.1136/ bmj.m1091

18. Parra-Bracamonte GM, Lopez-Villalobos N, Parra-Bracamonte FE (2020) Clinical characteristics and risk factors for mortality of patients with COVID-19 in a large data set from Mexico. AnnEpidemiolS1047-2797(20)30286-6. https:// doi.org/10.1016/j.annepidem.2020.08.005

19. Shestakova MV, Vikulova OK, Isakov MA, Dedov II (2020) Diabetes and COVID-19: analysis of the clinical outcomes according to the data of the Russian Diabetes Registry. ProblEndocrinol
66(1):35-46. (InRuss). https://doi.org/10.14341/ probl12458

20. Official internet portal of legal information. Publication date: 26.05.2020. Number of publication: 0001202005260023. (In Russ). https://publication.pravo.gov.ru/Document/View/ 0001202005260023 ? index $=4$ \& rangeSize $=1$

21. Shlyakhto EV, Arutyunov GP, Belenkov YuN, Tarlovskaya EI, Konradi AO, Panchenko EP, Yavelov IS, Tereshchenko SN, Ardashev AV, Arutyunov AG, Grigorieva NYu, Dzhunusbekova GA, Drapkina OM, Koziolova NA, Komarov AL, Kropacheva ES, Malchikova SV, Mitkovskaya NP, Orlova YaA, Petrova MM, Rebrov AP, Sisakian H, Skibitsky VV, Sugraliyev AB, Fomin IV, Chesnikova AI, Shaposhnik II, Zhelyakov EG, Kanorskii SG, Kolotsey LV, Snezhitskiy VA (2020) Use of Statins, Anticoagulants, Antiaggregants and Antiarrhythmic Drugs in Patients With COVID-19. The Agreed Experts' Position of Russian Society of Cardiology, Eurasian Association of Therapists, National Society on Atherothrombosis, Societies of Experts in Urgent Cardiology, Eurasian Arrhythmology Association. Kardiologiia 60(6):4-14. (In Russ). https://doi.org/ 10.18087/cardio.2020.6.n1180 5

22. Hu C, Liu Z, Jiang Y, Shi O, Zhang X, Xu K, Suo C, Wang Q, Song Y, Yu K, Mao X, Wu X, Wu M, Shi T, Jiang W, Mu L, Tully DC, Xu L, Jin L, Li S, Tao X, Zhang T, Chen X (2021) Early prediction of mortality risk among patients with severe COVID-19, using machine learning. Int $\mathbf{J}$ Epidemiol 49(6):1918-1929. https://doi.org/ 10.1093/ije/dyaa171

23. Russell CD, Millar JE, Baillie JK (2020) Clinical evidence does not support corticosteroid treatment for 2019-nCoV lung injury. Lancet 395(10223): 473-475. https://doi.org/10.1016/ S0140-6736(20)30317-2

24. Miao Y, Fan L, Li J-Y (2020) Potential Treatments for COVID-19 Related Cytokine Storm - Beyond Corticosteroids. Front Immunol 11:article 1445. https://doi.org/10.3389/fimmu.2020.01445

25. Kishkun AA (2006) Immunological and serological studies in clinical practice. OOO "Meditsinskoye Informatsionnoye Agentstvo". (In Russ).

Translated by A. Polyanovsky 